\title{
LEVEL OF THEORETICAL AND PRACTICAL TRAINING OF GENERAL PRACTIONERS-FAMILY PHYSICIANS FOR PROVISION OF THE COMPREHENSIVE REHABILITATION OF TARGET GROUPS OF THE ATTACHED POPULATION
}

\section{Ivats-Chabina A. R.}

\section{INTRODUCTION}

Nowadays, the need to provide rehabilitation services to target groups of population remains mostly unmet due to a number of factors, including the lack of accessible rehabilitation services outside urban areas and the longtime waiting for access to a rehabilitation center, lack of skilled rehabilitation specialists, and lack of resources, assistive technologies and devices, the use of ineffective means of rehabilitation by specialists, the high cost of rehabilitation services.

It is possible to solve the problem of providing the population with the necessary level of rehabilitation services by providing them on the basis of outpatient clinics and primary health care centers.

Relevance of work. Rehabilitation is an integral component of medical services, which guarantees that people, following illness, will be able to fully realize their functional potential in the conditions they live and work in.

Historically, rehabilitation had a low priority in the countries with limited investment in health care, which led to an underdeveloped, poorly coordinated system of rehabilitation services ${ }^{1,2}$.

Often, the high cost of training in rehabilitation centers and their geographical remoteness make patients refuse rehabilitation after discharge from the hospital, which significantly reduces the chances of a full recovery and slows down the recovery process.

WHO has identified the primary care unit as the principal tool to complete the task of achieving "health for all" and the foundation of the

${ }^{1}$ People-centred and integrated health services: an overview of the evidence: interim report. World Health Organization. 2015. URL: https://apps.who.int/iris/handle/ 10665/155004 (last accessed: 25.10.2019).

${ }^{2}$ Wilson RD, Lewis SA, Murray PK. Trends in the rehabilitation therapist workforce in underserved areas: 1980-2000. The Journal of Rural Health: official journal of the American Rural Health Association and the National Rural Health Care Association, 2009, Vol.25, № 1. P. 26-32. 
entire health care system ${ }^{3}$, and the general practitioners-family physicians is a central figure of primary care unit ${ }^{4}$.

Since January 2018, the reform of the medical industry began in Ukraine. One of its key tasks was the development of primary health care centers network and facilitate access to health care services, including rehabilitation ${ }^{5}$.

Due to the classification of rehabilitation stages, the hospital and sanatorium stages are provided by the relevant specialists of the secondary health care with active involvement of nursing staff and physical rehabilitators. However, immediately after discharge from the hospital, monitoring of the implementation of previous prescriptions, including physical measures, relies on the primary care staff. For example, in accordance with the Unified Clinical Protocols of the Ministry of Health of Ukraine as to the providing medical care for stroke, the family doctor should visit the patient up to three days after discharge, read the prescription from the hospital, including physical rehabilitation measures, motivate the patient to perform them, persuade him or her to persist in fulfilling the prescription.

The aim of this study is to examine the level of theoretical and practical training of general practitioners-family physicians as specialists of the basic level of medical care to ensure the comprehensive rehabilitation of target groups of the attached population.

Materials and methods. The special questionnaire was developed for the purpose of conducting this study, which included 4 blocks of questions. The questions concerned the readiness of GPs to provide medical rehabilitation services, the level of their theoretical and practical training for the provision of rehabilitation to patients with different nosologies, proposals to encourage physicians to provide rehabilitation care to target groups of populations and the opportunity to upgrade their qualification in this field.

3 Rehabilitation in health systems. World Health Organization. 2017. URL: https://apps.who.int/iris/bitstream/handle/10665/254506/9789241549974-eng.pdf? sequence $=8$ (last accessed: 22.10.2019).

4 Науково обгрунтовані підходи до кваліфікаційної характеристики лікаря загальної практики-сімейного лікаря з позиції компетентнісного підходу : методичні рекомендації / уклад. : Л.Ф. Матюха, Н.Г. Гойда, В.Г. Слабкий, М.В. Олійник. Київ : НМАПО ім. П.Л. Шупика, ДУ “УІСД МОЗ України”. 2010. 27 с.

${ }^{5}$ Про державні фінансові гарантії медичного обслуговування населення: Закон України від 19.10.2017 № 2168-VIII. URL: https://zakon.rada.gov.ua/laws/show/216819. (last accessed: 25.10.2019). 


\section{Data on GPs-family physicians who participated in the study}

The survey was attended by general practitioners - family doctors who are practicing specialists.

$87 \%$ of respondents are women, $13 \%$ - men.

The distribution by age was as follows:

$-6,5 \%$ of participants were under 25 years of age;

$-23,9 \%$ are $25-29$;

$-17,4 \%$ are $30-39$;

$-6,5 \%$ are $40-49$;

$-32,6 \%$ are $50-59$;

$-8,7 \%$ are $60-69$;

$-4.4 \%$ are 70 and over.

The total work experience as a doctor at $50 \%$ of the respondents is more than 20 years. 2,2\% work as a doctor for 15-19 years, 10,9\% - 10-14 years, $6,5 \%$ - from 6 to 9 years, $13 \%$ have a total work experience from 3 to 5 years and $17,4 \%$ - up to 2 years.

As a preparation for the work of a family doctor, $58,7 \%$ of the respondents had a specialization, $41.3 \%$ - an internship in family medicine.

According to the experience of working as a family doctor, the distribution was as follows:

- Up to 2 years work experience $-23,9 \%$;

$-3-5$ years $-17,4 \%$;

$-6-9$ years $-15,2 \%$;

$-10-14$ years $-17,4 \%$;

$-15-19$ years $-10,9 \%$;

-20 years and more $-15,2 \%$.

Absolutely all survey participants (100\%) indicated that they had undergone refresher training in the last 4 years.

$84.7 \%$ of the respondents work in cities, $15.3 \%$ - in countryside.

The data obtained during the sociological survey are statistically processed and analyzed.

Based on the data obtained during the study, conclusions were drawn and practical recommendations were developed.

Thus, the stage and structuring of the master's work are clearly defined, application of modern scientific methods ensured the obtaining of objective, scientifically substantiated conclusions.

In the study, $58.1 \%$ of the respondents reported that they had studied the issues of comprehensive rehabilitation of the target groups of population during the internship period. $41.9 \%$ did not study this issue during internship. 
$57.9 \%$ studied rehabilitation issues during pre-certification courses, $42.1 \%$ did not study.

During the thematic improvement courses $43.9 \%$ of respondents did not study the issue of providing rehabilitation services to target groups, $56.1 \%-$ did study.

Special trainings were held by $39.1 \%$ of respondents $(60.9 \%$ - did not), $58.7 \%$ attended scientific conferences on the topic of complex rehabilitation $(41.3 \%$ - did not).

Trainings in complex rehabilitation at the workplace was attended by $30,4 \%$ (69.9\% did not).

Regarding the work on scientific and medical literature, which covers issues of complex rehabilitation, $43.5 \%$ of respondents reported that they regularly work with new scientific sources. $45.7 \%$ reported that they often work on scientific and medical works. $6.5 \%$ of respondents do not work on scientific and medical literature and $4.3 \%$ were unable to give an accurate answer.

At the same time, $69.9 \%$ of respondents said they were interested in the scientific literature on medical rehabilitation. $26,1 \%$ chose the "partial" option and 4,3\%. could not decide on the answer.

\section{The expediency of transferring medical rehabilitation measures on an outpatient basis to the family doctor and personal readiness to provide rehabilitation services}

The survey found that $52,2 \%$ of respondents considered it advisable to delegate responsibilities for providing medical rehabilitation to family doctors.

$28.8 \%$ of respondents voted against it.

$19,6 \%$ could not determine.

Prescription of medical rehabilitation in case of need. $60.9 \%$ of family physicians who participated in the survey stated that they prescribe medical rehabilitation to their patients, if necessary, $15,2 \%$ - do not prescribe, $23,9 \%$ of respondents could not answer.

The possibility of prescription of medical rehabilitation measures for patients. Regarding the possibility of prescribing medical rehabilitation to all patients who need it, the distribution was as follows: $43.5 \%$ of respondents said they have such opportunity. Another 32,6\% reported that they cannot prescribe medical rehabilitation measures to patients when needed.

$23,9 \%$ were unable to answer.

Possibility of receiving consultations for carrying out medical rehabilitation measures to patients from other specialists. A prerequisite for choosing the optimal rehabilitation method is the contact of the family 
doctor with physicians of other specialities and the possibility of additional methods of patient examination.

$39.1 \%$ of the respondents reported that they have difficulties in obtaining consultations for medical rehabilitation measures for patients from other specialists.

$30,4 \%$ replied that they have such difficulties in the vast majority of cases.

$15,2 \%$ of the respondents mostly had no problems in obtaining consultations from other specialists.

$13 \%$ of respondents did not have the similar problem at all, and $1.2 \%$ were unable to answer.

\section{The level of theoretical training of general practitioners \\ to provide comprehensive rehabilitation of target groups of the attached population}

Respondents rated their level of theoretical training on rehabilitation as follows:

$26,1 \%$ rated their level as sufficient;

$19,6 \%$ consider their level rather sufficient than insufficient;

$21,7 \%$ consider their level more insufficient than sufficient ;

$26,1 \%$ consider their level of theoretical training insufficient;

$6,5 \%$ reported a complete lack of training;

The level of theoretical training on the issues of complex rehabilitation of patients with diseases of the peripheral nervous system:

$21,7 \%$ rated their theoretical background as sufficient.

Another $21,7 \%$ consider their level more sufficient than insufficient.

$28,3 \%$ consider their level more insufficient than sufficient.

$21,7 \%$ consider their level of theoretical training to be insufficient.

$6,5 \%$ of respondents reported a complete lack of theoretical training in conducting comprehensive rehabilitation of patients with pathologies of the peripheral nervous system.

The level of theoretical training on the issues of complex rehabilitation of patients with diseases of the central nervous system:

Sufficient level of preparation for complex rehabilitation of patients with CNS diseases was reported by $21,7 \%$ of the respondents.

$23,9 \%$ consider their level more sufficient than insufficient. $19,6 \%$ of the respondents consider their level more insufficient than sufficient.

$23,9 \%$ rated their theoretical preparation as insufficient.

$6,5 \%$ of respondents reported a complete lack of theoretical training in this field.

$4,3 \%$ were not able to answer this question. 
The level of theoretical training on the issues of complex rehabilitation of patients with diseases of the circulatory system:

A sufficient level of theoretical training is at $28,3 \%$ of respondents.

$34,8 \%$ consider their level more sufficient than insufficient.

$15,2 \%$ consider their level of theoretical training more insufficient than sufficient.

$13 \%$ of respondents consider their theoretical preparation for rehabilitation of patients with circulatory system diseases insufficient.

$4,3 \%$ could not answer.

The level of theoretical training on the issues of complex rehabilitation of patients with respiratory diseases:

$32,6 \%$ of respondents have sufficient theoretical training in rehabilitation of patients with respiratory pathologies.

$28,3 \%$ rated their level as more sufficient than insufficient.

$21,7 \%$ consider their level of preparation more insufficient than sufficient.

Insufficient level of theoretical training is at $10,9 \%$.

$2,2 \%$ of respondents reported a complete lack of training and $4,3 \%$ could not decide.

The level of theoretical training on the issues of complex rehabilitation of patients with diseases of the digestive system:

$39.1 \%$ of respondents rated their training level as sufficient. More sufficient than insufficient level of theoretical training is at $23,9 \%$.

$19,6 \%$ consider their level to be more insufficient than sufficient.

Insufficient level of theoretical training is at $13 \%$ of respondents.

A total lack of training was reported by $4,3 \%$ of respondents.

The level of theoretical training on the issues of complex rehabilitation of patients with diseases of the musculoskeletal system:

$26,1 \%$ of the doctors who participated in this survey believe that they have a sufficient level of theoretical knowledge on the rehabilitation of patients with diseases of the musculoskeletal system.

$30,4 \%$ described their level as more sufficient than insufficient, $15,2 \%-$ as more insufficient than sufficient.

$21,7 \%$ identified their level of theoretical training as insufficient for rehabilitation of patients with pathologies of the musculoskeletal system.

$2,2 \%$ of the respondents noted a complete lack of training on this issue.

$4,3 \%$ could not answer.

The level of theoretical training on the issues of complex rehabilitation of patients with injuries of the musculoskeletal system:

$19,6 \%$ of doctors consider their level of preparation for providing rehabilitation assistance to patients with musculoskeletal injuries as sufficient. 
$26,1 \%$ described their level as more sufficient than insufficient.

26,1\%.- as more insufficient than sufficient.

$19,6 \%$ of the respondents consider the level of their own theoretical knowledge in this field to be absolutely insufficient.

$4,3 \%$ reported a complete lack of training on this issue.

$4,3 \%$ could not decide.

The level of theoretical training on the issues of complex rehabilitation of patients with various types of addictions (tobacco, alcohol, drug):

Only $21,7 \%$ of the respondents believe that they have a sufficient level of theoretical training for complex rehabilitation of patients with addiction.

$15,2 \%$ consider their training level more sufficient than insufficient. $19,6 \%$ - as more insufficient than sufficient.

$23,9 \%$ said that their level of theoretical training was absolutely insufficient.

$13 \%$ reported a complete lack of such training.

$6,5 \%$ of the respondents could not answer the question.

The level of theoretical training on the issues of complex rehabilitation of patients after undergoing surgical interventions on different organs:

$17,4 \%$ of respondents rated their level of training in this field as sufficient.

$15,2 \%$ consider their level of theoretical training as more sufficient than insufficient. $24.4 \%$ of the respondents consider that the level of their own theoretical training on this issue is more insufficient than sufficient.

$32,6 \%$ said that their level of theoretical training was absolutely insufficient.

A total lack of theoretical training is noted by $10,9 \%$.

The level of theoretical training on the issues of comprehensive rehabilitation of children:

$28,3 \%$ of respondents consider their level of theoretical knowledge for providing comprehensive rehabilitation to children sufficient.

$15,2 \%$ believe that their theoretical background is more sufficient than insufficient. $23,9 \%$ rate their level of theoretical training on this issue as more insufficient than sufficient. 19,6\% of respondents have insufficient knowledge in this field.

Another $13 \%$ reported a complete lack of theoretical training for comprehensive rehabilitation of children.

The level of theoretical training on the issues of complex rehabilitation of the disabled:

$17,4 \%$ rated their theoretical background as sufficient.

$15,2 \%$ consider it more sufficient than insufficient. 
$26,1 \%$ consider their level of preparation for rehabilitation of the disabled as more insufficient than sufficient. 30,4\% of respondents have insufficient knowledge in this field. 10,9\% reported a complete lack of theoretical background on the subject.

The level of theoretical training on the issues of comprehensive rehabilitation of the elderly:

$19,6 \%$ consider their level of theoretical background to be sufficient. $32,6 \%$ consider it more sufficient than insufficient.

$19,6 \%$ consider their theoretical background to be more insufficient than sufficient.

Another 19,6\% consider their level of theoretical knowledge in the field of rehabilitation of the elderly as insufficient.

A total lack of training is in $8,7 \%$ of respondents.

The data obtained are shown in Table 1.

Table 1

The level of theoretical training of general practitioners-family physicians to provide rehabilitation assistance

\begin{tabular}{|c|c|c|c|c|c|c|}
\hline \multicolumn{7}{|c|}{ The level of theoretical training (\%) } \\
\hline Level of training & 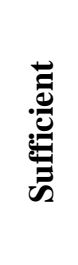 & 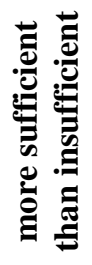 & 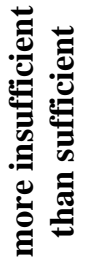 & 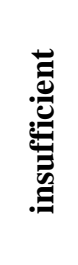 & 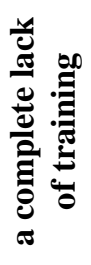 & 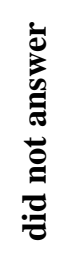 \\
\hline In general & 26,1 & 19,6 & 21,7 & 26,1 & 6,5 & 0 \\
\hline $\begin{array}{l}\text { Diseases of the peripheral } \\
\text { nervous system }\end{array}$ & 21,7 & 21,7 & 28,3 & 21,6 & 6,5 & 0 \\
\hline $\begin{array}{l}\text { Diseases of the central } \\
\text { nervous system }\end{array}$ & 21,7 & 23,9 & 19,6 & 23,9 & 6,5 & 4,3 \\
\hline $\begin{array}{l}\text { Diseases of the circulatory } \\
\text { system }\end{array}$ & 28,3 & 34,8 & 15,2 & 13 & 0 & 4,3 \\
\hline Respiratory diseases & 32,6 & 28,3 & 21,7 & 10,9 & 2,2 & 4,3 \\
\hline Digestive diseases & 39,1 & 23,9 & 19,6 & 13 & 4,3 & 0 \\
\hline $\begin{array}{l}\text { Diseases of the } \\
\text { musculoskeletal system }\end{array}$ & 26,1 & 30,4 & 15,2 & 21,7 & 2,2 & 4,3 \\
\hline
\end{tabular}


Table 1 (ending)

\begin{tabular}{|l|c|c|c|c|c|c|}
\hline \multicolumn{7}{|c|}{ The level of theoretical training (\%) } \\
\hline Novel of training & & & & & \\
\hline $\begin{array}{l}\text { Injuries to the the } \\
\text { musculoskeletal system }\end{array}$ & 19,6 & 26,1 & 26,1 & 19,6 & 4,3 & 4,3 \\
\hline $\begin{array}{l}\text { Tobacco, alcohol and drug } \\
\text { addiction }\end{array}$ & 21,7 & 15,2 & 19,6 & 23,9 & 13 & 6,5 \\
\hline $\begin{array}{l}\text { Surgical interventions on } \\
\text { different organs }\end{array}$ & 17,4 & 15,2 & 24,4 & 32,6 & 10,9 & 0 \\
\hline Rehabilitation of children & 28,3 & 15,2 & 23,9 & 19,6 & 13 & 0 \\
\hline Rehabilitation of the disabled & 17,4 & 15,2 & 26,1 & 30,4 & 10,9 & 0 \\
\hline Rehabilitation of the elderly & 19,6 & 32,6 & 19,6 & 19,6 & 8,7 & 0 \\
\hline
\end{tabular}

The highest level of theoretical training of respondents was noted in the following areas: diseases of the digestive system, diseases of the respiratory system, pathology of the circulatory system. The largest number of respondents positively (as sufficient or more sufficient than insufficient) rated their theoretical preparation for the rehabilitation of patients was with nosologies.

The lowest level of training is in the field of rehabilitation of disabled people, the elderly and patients after surgery. Responding to these questions, the respondents gave the highest number of negative assessments (more insufficient than sufficient and insufficient level of training, complete lack of preparation for providing rehabilitation assistance to these groups of patients). The generalized level of theoretical training of GPs-family doctors to provide rehabilitation assistance based on the results of a sociological survey is given in Table 1 .

4. Level of practical training of general practitioners to provide comprehensive rehabilitation of the target groups of the attached population

Respondents assessed the level of their practical training for providing comprehensive rehabilitation to the target population as follows: 
$17,4 \%$ of the respondents consider their level of practical training sufficient to provide rehabilitation services to the target groups of population.

$19,6 \%$ rated their level of practical training as more sufficient than insufficient.

$34,8 \%$ consider their level of practical training to be more insufficient than sufficient.

$23,9 \%$ reported a lack of practical training.

$4,3 \%$ failed to answer.

None of the respondents rated their practical skills as insufficient.

Level of practical training on the issues of complex rehabilitation of patients with diseases of the peripheral nervous system:

Only 15,2\% consider their level as sufficient.

$21,7 \%$ rated their level of practical training as more sufficient than insufficient.

$30,4 \%$ rated their level of practical training in the rehabilitation of patients with diseases of the peripheral nervous system as more insufficient than sufficient.

$28,3 \%$ consider their level of practical knowledge in the field as insufficient and 4,3\% reported a complete lack of practical training.

Level of practical training on the issues of complex rehabilitation of patients with diseases of the central nervous system:

For the comprehensive rehabilitation of patients with central nervous system diseases, $15,2 \%$ of respondents have a sufficient level of preparation.

$17,4 \%$ rated their level of practical training as more sufficient than insufficient.

$28,3 \%$ have more insufficient than sufficient level of practical training.

$32,6 \%$ said that their level of theoretical training was absolutely insufficient.

Total lack of training is in 6,5\% of respondents.

Level of practical training on the issues of complex rehabilitation of patients with diseases of the circulatory system:

$22,2 \%$. have sufficient level of practical training on the subject.

$26.7 \%$ find their practical training level more sufficient than insufficient.

$33.3 \%$ of the respondents have more insufficient than sufficient level of practical training.

$13 \%$ were assessed their level of practical training as insufficient, and $4,3 \%$ reported a complete lack of training.

$2,2 \%$ could not answer. 
Level of practical training on the issues of complex rehabilitation of patients with respiratory diseases:

$23,9 \%$ of survey participants have sufficient level of training for comprehensive rehabilitation of patients with respiratory disorders.

$28,3 \%$ reported more adequate than insufficient level of training.

$23,9 \%$ of respondents have more insufficient than sufficient level of practical training.

Insufficient level of practical training is at $15,2 \%$ of respondents.

$2,2 \%$ of respondents have a complete lack of training.

$4,3 \%$ could not decide.

Level of practical training on the issues of complex rehabilitation of patients with diseases of the digestive system:

A sufficient level of practical training is in $23,9 \%$ of respondents.

$30,4 \%$ reported more sufficient than insufficient level of training.

$21,7 \%$ of respondents have more insufficient than sufficient level of practical training.

Insufficient level of practical skills to provide rehabilitation services to persons with digestive disease is at $15,2 \%$ of respondents.

A complete lack of training is in 4,3\% and 4,3\% did not answer.

Level of practical training on the issues of comprehensive rehabilitation of patients with diseases of the musculoskeletal system:

$17,4 \%$ have sufficient practical skills in this area.

$23,9 \%$ consider their skills level to be more sufficient than insufficient.

$28,3 \%$ consider their level of practical training as more insufficient than sufficient.

$17,4 \%$ of respondents have insufficient level of practical skills in the field of complex rehabilitation for people with musculoskeletal disorders.

$6,5 \%$ reported a complete lack of practical training.

$6,5 \%$ could not answer.

Level of practical training on the issues of complex rehabilitation of patients with injuries of the musculoskeletal system:

$15,2 \%$ of respondents have sufficient level of practical training for carrying out complex rehabilitation of persons with injuries of the musculoskeletal system.

$19,6 \%$ consider their level of practical training to be more sufficient than insufficient.

$34,8 \%$ consider their level of practical training as more insufficient than sufficient.

$17,4 \%$ have insufficient level of practical training.

$4,3 \%$ reported a complete lack of practical training.

$8,7 \%$ could not answer. 
Level of practical training on the issues of complex rehabilitation of patients with different types of addictions (tobacco, alcohol, drugs):

$21,7 \%$ of respondents have a sufficient level of practical skills for rehabilitation of people with addictions.

$13 \%$ believe that their practical skills are more sufficient than insufficient.

$24 \%$ rated their level as more insufficient than sufficient.

$15,2 \%$ of respondents have no practical training at all.

$2,2 \%$ could not answer.

Level of practical training on the issues of complex rehabilitation of patients after undergoing surgical interventions on different organs:

Sufficient level of practical training for rehabilitation assistance to persons after undergoing surgery is in $17,4 \%$ of the respondents.

$13 \%$ consider their level of practical training to be more sufficient than insufficient.

$32,6 \%$ of the respondents rate their level of preparation as more insufficient than sufficient.

Insufficient level of practical training is in $23,9 \%$.

$8,7 \%$ have no practical training and $4,3 \%$ could not answer.

Level of practical training on the issues of comprehensive rehabilitation of children:

$26,1 \%$ of the surveyed physicians have sufficient level of practical training of child rehabilitation.

$13 \%$ consider their level of practical training to be more sufficient than insufficient.

$21,7 \%$ rate their level of preparation as more insufficient than sufficient.

Insufficient level of practical training is at $15,2 \%$.

$15,2 \%$ reported a complete lack of training on this issue and $8,7 \%$ did not answer.

Level of practical training on the issues of complex rehabilitation of the disabled:

$15,2 \%$ of respondents have a sufficient level of practical training.

$17,4 \%$ rate it as more sufficient than insufficient.

$28,3 \%$ said they considered their level as more insufficient than sufficient.

$21,7 \%$ report that their level of practical training is insufficient.

$10,9 \%$ said they did not have the practical skills to provide rehabilitation services to persons with disabilities.

$6,5 \%$ could not answer.

The level of theoretical training on the issues of comprehensive rehabilitation of the elderly: 
$15,2 \%$ of the respondents have a sufficient level of preparation for the rehabilitation of the elderly.

$26,1 \%$ said they rate their level more sufficient than insufficient.

$23,9 \%$ consider their training to more insufficient than sufficient.

$21,7 \%$ said that their practical training in this field is insufficient.

$6,5 \%$ reported a lack of practical training.

$6,5 \%$ of respondents did not answer.

The table 2 shows the results of a survey on the practical training of primary care physicians to provide rehabilitation to target groups of populations.

Table 2

Level of practical training of general practitioners-family physicians to provide rehabilitation assistance

\begin{tabular}{|l|l|l|l|l|l|l|}
\hline \multicolumn{7}{|c|}{ The level of practical training\% } \\
\hline Nosel of training & & & & & \\
\hline In general & 17,4 & 19,6 & 34,8 & 23,9 & 0 & 4,3 \\
\hline $\begin{array}{l}\text { Diseases of the peri- } \\
\text { pheral nervous system }\end{array}$ & 15,2 & 21,7 & 30,4 & 28,3 & 4,3 & 0 \\
\hline $\begin{array}{l}\text { Diseases of the central } \\
\text { nervous system }\end{array}$ & 15,2 & 17,4 & 28,3 & 32,6 & 6,5 & 0 \\
\hline $\begin{array}{l}\text { Diseases of the } \\
\text { circulatory system }\end{array}$ & 21,7 & 26,1 & 32,6 & 13 & 4,3 & 2,2 \\
\hline Respiratory diseases & 23,9 & 28,3 & 23,9 & 15,2 & 2,2 & 4,3 \\
\hline Digestive diseases & 23,9 & 30,4 & 21,7 & 15,2 & 4,3 & 4,3 \\
\hline $\begin{array}{l}\text { Diseases of the } \\
\text { musculoskeletal system }\end{array}$ & 17,4 & 23,9 & 28,3 & 17,4 & 6,5 & 6,5 \\
\hline $\begin{array}{l}\text { Injuries to the the } \\
\text { musculoskeletal system }\end{array}$ & 15,2 & 19,6 & 34,8 & 17,4 & 4,3 & 8,7 \\
\hline $\begin{array}{l}\text { Tobacco, alcohol and } \\
\text { drug addiction }\end{array}$ & 21,7 & 13 & 26,1 & 24 & 15,2 & 2,2 \\
\hline
\end{tabular}


Table 2 (ending)

\begin{tabular}{|c|c|c|c|c|c|c|}
\hline \multicolumn{7}{|c|}{ The level of practical training\% } \\
\hline Level of traini & 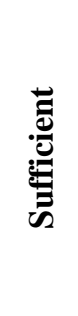 & 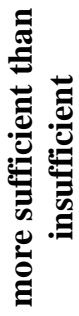 & 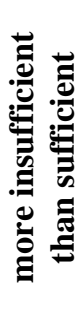 & 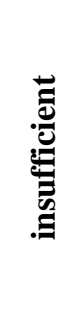 & 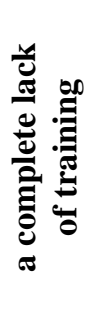 & 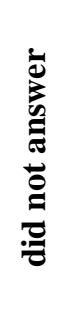 \\
\hline $\begin{array}{l}\text { Surgical interventions } \\
\text { on different organs }\end{array}$ & 17,4 & 13 & 32,6 & 23,9 & 8,7 & 4,3 \\
\hline Rehabilitation of children & 26,1 & 13 & 21,7 & 15,2 & 15,2 & 8,7 \\
\hline $\begin{array}{l}\text { Rehabilitation } \\
\text { of the disabled }\end{array}$ & 15,2 & 17,4 & 28,3 & 21,7 & 10,9 & 6,5 \\
\hline $\begin{array}{l}\text { Rehabilitation } \\
\text { of the elderly }\end{array}$ & 15,2 & 26,1 & 23,9 & 21,7 & 6,5 & 6,5 \\
\hline
\end{tabular}

The highest level of practical training of the respondents was noted in the following areas: rehabilitation of children, patients with pathology of respiratory organs and digestive organs - here the respondents gave the highest positive assessments of their practical skills.

The lowest level of training in the field was with rehabilitation of the disabled, rehabilitation of patients with pathologies of the central nervous system and injuries of the musculoskeletal system.

In these points, the majority of respondents rated their level as more insufficient than sufficient and insufficient.

\section{Possibilities of improving the system of rehabilitation at the primary level of providing medical care}

The general practitioners who participated in the survey were asked to choose from the list of rehabilitation services that they consider appropriate to transmit to family physicians. The distribution was as follows:

$-57.8 \%$ consider it to be necessary to use an individual approach for the rehabilitation of patients from the target groups of population.

$-44.4 \%$ consider it to be necessary for family doctors to conduct physiotherapy procedures.

$-42,2 \%$ believe that family physicians should have an exercise therapy session with patients. 
$-33.3 \%$ would choose to carry out comprehensive measures to rehabilitate the target groups of the attached population.

$-31.3 \%$ consider it advisable to use psychotherapy to work with patients.

$-26.7 \%$ would choose to carry out domestic rehabilitation activities.

$-22,2 \%$ voted in favor of therapeutic massage.

$-17.8 \%$ consider it necessary to carry out social rehabilitation measures for patients from the target groups of population.

Regarding the forms of preparation of family doctors for complex rehabilitation of patients, $39.1 \%$ of the respondents consider special trainings as the best form of training. $21,7 \%$ would prefer an internship at the workplace. $19,6 \%$ would choose full-time study, $8,7 \%$ - correspondence. $10,9 \%$ of respondents would choose the blended (part-time) form of training to provide rehabilitation services.

When they were asked "Would you like to use medical rehabilitation in your activity?" $69.9 \%$ of respondents gave the positive answer. $2,2 \%$ did not want to use rehabilitation tools in their work and $28,3 \%$ could not decide.

Among the proposed mechanisms to encourage family doctors to use medical rehabilitation facilities, $60.8 \%$ spoke in favor of higher wages. $47.8 \%$ would like to carry out medical rehabilitation as additional paid services. $2,2 \%$ of respondents would choose one-time financial incentives.

When they were asked "Who should develop a medical rehabilitation complex for use by a family doctor?" the respondents answered as follows:

$84.4 \%$ believe that the development of a MR complex should be handled by a rehabilitation physician

$11.1 \%$ believe that a rehabilitation commission should be involved in this activity

$2,2 \%$ believe that this function should be performed by a family doctor.

$2,2 \%$ believe that joint development of a rehabilitation program by a family doctor and a rehabilitation doctor will be the best option

Respondents were asked to name specialties in which they believed patients could be referred for medical rehabilitation to a family doctor. Respondents believe that patients with cardiovascular pathology, pulmonary patients, patients with diseases of the digestive system, neurological patients and patients after the trauma can be transferred for rehabilitation to family doctors.

The survey participants were also asked to evaluate the compliance of their outpatient facilities with the conditions of rehabilitation activities. $78.3 \%$ believe that family medicine dispensaries do not have the necessary conditions. $8,7 \%$ believe that the family clinic they work in has the necessary logistical support for medical rehabilitation. $13 \%$ were not able to answer this question. 
Among the suggestions for optimizing the organization of provision of medical rehabilitation services, the survey participants named the following:

- Improvement of the material base of family medicine dispensaries.

- Arrangement of physiotherapy and massage rooms, establishment of an outpatient therapeutic physical training room.

- Creation of a position of a rehabilitation physician on the basis of a family medicine clinic.

- Wage increases and regular bonuses.

- Conducting additional training, seminars and rehabilitation courses.

- Increase the number of junior medical staff (nurses).

\section{CONCLUSIONS}

The results obtained during a sociological survey among family doctors indicated that they had insufficient level of theoretical and practical training for providing rehabilitation of population. At the same time, the data obtained indicate that family doctors in their majority support the integration of rehabilitation services at the primary level and offer realistic steps for this purpose.

The highest level of theoretical training of the respondents was noted in the following areas: digestive diseases (39.1\% rated their level as sufficient, $23,9 \%$ rated their level as more sufficient than insufficient, 19,6\% had more insufficient than sufficient level of theoretical training, 13\% considered their level of theoretical training insufficient, $4,3 \%$ reported a complete lack of training on this issue), respiratory diseases $(32,6 \%$ had sufficient level of theoretical training, $28,3 \%$ rated their level as more sufficient than insufficient, $21,7 \%$ had more insufficient than sufficient level of theoretical training, 10,9\% considered their level of theoretical training insufficient and $2,2 \%$ reported a complete lack of training on this issue), pathology of the blood system turnover $(28,3 \%$ had sufficient level of theoretical training, $34,8 \%$ rated their level as more sufficient than insufficient).

The lowest level of theoretical training is on rehabilitation of the disabled (only 17,4\% of respondents had sufficient level of theoretical training and $15,2 \%$ rated their level as more sufficient than insufficient, $26,1 \%$ had more insufficient than sufficient level of theoretical training, 30,4\% considered their level of theoretical training insufficient and 10,9\% reported a complete lack of training on this issue), rehabilitation of elderly (only 19,6\% had a sufficient level of theoretical training, 32,6\% rated their level as more sufficient than insufficient, $19,6 \%$ had more insufficient than sufficient level of theoretical training, 19,6\% had insufficient level of theoretical training, $8,7 \%$ reported a complete lack of training on this issue), and rehabilitation of patients after surgery (only $17,4 \%$ had a sufficient level of theoretical 
training and 15,2\% rated their level as more sufficient than insufficient, $24.4 \%$ had more insufficient than sufficient level of theoretical training, $32,6 \%$ considered their level of theoretical training insufficient and $10,9 \%$ reported a complete lack of training on this issue).

Respondents have the highest level of practical training in such areas as rehabilitation of children $(26,1 \%$ had sufficient level of practical training, $13 \%$ rated their level as more sufficient than insufficient, $21,7 \%$ had more insufficient than sufficient level of practical training, 15,2\% had insufficient level of training, another $15,2 \%$ reported a complete lack of practical training), patients with respiratory tract pathology $(23,9 \%$ had sufficient level of practical training, 28,3\% rated their level as more sufficient than insufficient, $23,9 \%$ had more insufficient than sufficient level of practical training, $15,2 \% \%$ had insufficient level of training and 2,2\%\% reported a complete lack of practical training), patients with diseases of the digestive system $(23,9 \%$ had sufficient level of practical training, 30,4\% rated their level as more sufficient than insufficient, $21,7 \%$ had more insufficient than sufficient level of practical training, 15,2\% have insufficient TPT, $4,3 \%$ reported a complete lack of practical training). For these nosologies, the respondents gave the highest positive assessment of their practical skills.

The lowest level of practical training of respondents on such issues as rehabilitation of persons with disabilities (only $15,2 \%$ had sufficient level of practical training, $17,4 \%$ rated their level as more sufficient than insufficient, $28,3 \%$ had more insufficient than sufficient level of practical training, $21,7 \%$ had insufficient level of training and 10,9\% reported a complete lack of practical training), rehabilitation of patients with pathologies of the central nervous system $(15,2 \%$ had sufficient level of practical training, $17,4 \%$ rated their level as more sufficient than insufficient, $28,3 \%$ had more insufficient than sufficient level of practical training, 32,6\% had insufficient level of training) and injuries of the musculoskeletal system $(15,2 \mathrm{had}$ sufficient level of practical training, 19,6\% rated their level as more sufficient than insufficient, $34,8 \% \%$ had more insufficient than sufficient level of practical training, $17,4 \% \%$ had insufficient level of training, $4,3 \%$ reported a complete lack of practical training). In these points, the majority of respondents rated their level as more insufficient than sufficient insufficient.

During the comparison of the obtained indicators of practical training and theoretical training, it was found that the level of theoretical and practical training of primary care physicians to provide rehabilitation to patients with pathologies of respiratory system, digestive system and diseases of the cardiovascular system is the highest. The lowest level of training is in such areas as rehabilitation of patients after surgery and injuries 
of the musculoskeletal system (here respondents gave the highest number of negative assessments on both theoretical and practical training).

The majority of respondents expressed a desire to use the methods of medical rehabilitation in their practice.

According to the respondents, patients with cardiovascular pathology, pulmonary patients, patients with digestive diseases, neurological patients and patients after traumatic injuries may be referred for rehabilitation to family doctors.

\section{SUMMARY}

The study of theoretical and practical training of general practitionersfamily physicians, as specialists of basic level of medical assistance to ensure the comprehensive rehabilitation of the target groups of assigned population. The aim of this study is to examine the level of theoretical and practical training of general practitioners-family physicians as specialists of the basic level of medical care to ensure the comprehensive rehabilitation of target groups of the attached population. Materials and methods. A special questionnaire was developed for the purpose of conducting this study, which included 4 blocks of questions. The questions concerned the readiness of GPs to provide medical rehabilitation services, the level of their theoretical and practical training for the provision of rehabilitation to patients with different nosologies, proposals to encourage physicians to provide rehabilitation care to target groups of populations and the opportunity to upgrade their skills in this field. Conclusions. The highest is the level of theoretical and practical training of primary care physicians to provide rehabilitative care to patients with pathologies of the respiratory system, digestive system and cardiovascular system diseases. The lowest is level of training in areas such as rehabilitation of patients after surgical interventions and injuries of the musculoskeletal system (here respondents gave the highest number of negative assessments on both theoretical and practical training). Overall, today, the level of training of primary care physicians is insufficient to provide rehabilitation services based on the facilities of primary health care centers.

\section{REFERENCES}

1. People-centred and integrated health services: an overview of the evidence: interim report. World Health Organization. 2015. URL: https://apps.who.int/iris/handle/10665/155004 (last accessed: 25.10.2019).

2. Rehabilitation in health systems. World Health Organization. 2017. URL: https://apps.who.int/iris/bitstream/handle/10665/254506/9789241549974eng.pdf? sequence $=8$ (last accessed: 22.10 .2019 ). 
3. Wilson RD, Lewis SA, Murray PK. Trends in the rehabilitation therapist workforce in underserved areas: 1980-2000. The Journal of Rural Health: official journal of the American Rural Health Association and the National Rural Health Care Association. 2009. Vol. 25. № 1. P. 26-32.

4. Науково обгрунтовані підходи до кваліфікаційної характеристики лікаря загальної практики-сімейного лікаря 3 позиції компетентнісного підходу : методичні рекомендації / уклад. : Л.Ф. Матюха, Н.Г. Гойда, В.Г. Слабкий, М.В. Олійник. Київ : НМАПО ім. П. Л. Шупика, ДУ “УІСД МОЗ України”. 2010. 27 с.

5. Про державні фінансові гарантії медичного обслуговування населення : Закон України від 19.10.2017 № 2168-VIII. URL: https://zakon.rada.gov.ua/laws/show/2168-19. (last accessed: 25.10.2019).

\section{Information about author:} Ivats-Chabina A. R., Assistant of the Department of Health Sciences of the Faculty of Health and Physical Education Uzhhorod National University 3, Narodna Sq., Uzhhorod, 88000, Ukraine 